\title{
Comparing Efficacies of 0.5\% Apraclonidine with 4\% Cocaine in the Diagnosis of Horner Syndrome in Pediatric Patients
}

\author{
PO-LIANG CHEN, ${ }^{1}$ JIANN-TORNG CHEN, ${ }^{1}$ DA-WEN LU, ${ }^{1}$ YO-CHANG CHEN, ${ }^{2}$ \\ and CHIH-HSIEN HSIAO ${ }^{1}$
}

\begin{abstract}
Purpose: The aim of this study was to compare the efficacy of $0.5 \%$ apraclonidine with that of $4 \%$ cocaine and to evaluate its safety in the diagnosis of Horner syndrome in pediatric patients.

Methods: This was a randomized, crossover study, wherein 10 patients with a probable diagnosis of Horner syndrome were assigned to undergo pharmacological testing with $4 \%$ cocaine and $0.5 \%$ apaconidine. The difference in the pupil diameters of each eye was recorded under dim light before and $1 \mathrm{~h}$ after $0.5 \%$ apraclonidine or $4 \%$ cocaine was instilled. Any adverse effects were noted during examination or reported by the patients' parents were recorded.

Results: The mean differences in pupil diameter before and after $4 \%$ cocaine testing were -2.08 and $-2.97 \mathrm{~mm}$, respectively $(P=0.0047)$. All patients had an anisocoria greater than $1 \mathrm{~mm}$ after $4 \%$ cocaine testing. The mean difference in pupil diameter before and after $0.5 \%$ apraclonidine was instilled were -2.04 and $+1.08 \mathrm{~mm}$, respectively $(P=0.005)$. All patients showed a reversal of anisocoria after $0.5 \%$ apraclonidine testing. Conjunctival hyperemia was noted in 2 patients, but systemic adverse effects were not noted during examination nor reported by the patients' parents.

Conclusions: The application of $0.5 \%$ apraclonidine in pediatric patients is safe and effective in the diagnosis of Horner syndrome.
\end{abstract}

\section{INTRODUCTION}

$\mathbf{H}$ ORNER SYNDROME is caused by an interruption to the sympathetic innervation of the eye and ocular adnexae, which may occur at any point along the three-neuron pathway from the hypothalamus to the orbit. ${ }^{1}$ The clinical signs of Horner syndrome are pupillary miosis and blepharoptosis. Heterochromia iridis, enophthal- mos, defective accommodation, and facial anhidrosis may also be observed. ${ }^{2}$ The pathological processes responsible for this sympathetic denervation in pediatric patients range from birth trauma to life-threatening conditions, such as neuroblastoma and brainstem vascular malformation. ${ }^{3}$ Timely diagnosis and appropriate evaluation are important for life-saving intervention.

Topical cocaine has been widely used for the

\footnotetext{
${ }^{1}$ Department of Ophthalmology, Tri-Service General Hospital, National Defense Medical Center, Taipei, Taiwan Republic of China.

${ }^{2}$ Department of Ophthalmology, Tri-Service General Hospital, Taipei Medical University, Taipei, Taiwan, Republic of China.
} 
definite confirmation of suspected Horner syndrome. ${ }^{4-6}$ Cocaine inhibits the reuptake of norepinephine at the synaptic junction of the postganglionic fibers and the iris dilator muscle. If the sympathetic innervation is disrupted, norepinephine cannot be released from the nerve terminal, and topical cocaine does not produce pupillary dilation. ${ }^{5}$ Apraclonidine hydrochloride is an $\alpha$-adrenergic receptor agonist with strong $\alpha 2$ and weak $\alpha 1$ activity and is approved for the treatment of elevated intraocular pressure (IOP) following argon laser trabeculoplasty. In a previous study, apraclonidine was effective in the diagnosis of Horner syndrome, based on its $\alpha 1$ adrenergic activity, at concentrations of $1 \%$ and $0.5 \% .^{7-9}$ To our knowledge, this is the first study to compare the efficacy of $0.5 \%$ apraclonidine with that of $4 \%$ cocaine in the diagnosis of Horner syndrome and to evaluate its safety in pediatric patients.

\section{METHODS}

In this randomized, crossover study, 10 consecutive pediatric patients with known or newly probable diagnosed Horner syndrome were recruited. The study was approved by the Ethics Committee for Human Study of the Tri-Service General Hospital Clinical Research Institute (Tapei, Taiwan, Republic of China). The probable diagnoses of Horner syndrome were based on clinical history, the presence of miosis and ptosis on the same side, dilation lag, and the absence of other causes of anisocoria. All patients received a complete ophthalmologic examination plus a neurological assessment, urine test ( $24 \mathrm{~h}$ homovanillic and vanillylmandelic acid), and imaging studies magnetic resonance imaging ([MRI] of head/neck, abdominal computed tomography [CT]).

After informed consent was obtained from the patients' parents, the difference in the two pupil diameters of each patient (anisocoria) was measured photographically under dim light before pharmacological testing. Patients were randomized to receive 1 drop of $4 \%$ cocaine or $0.5 \%$ apraclonidine (Iopidine; Alcon, Fort Worth, TX) into each eye 1 week apart, and the parents of the patients were instructed to place pressure over the lacrimal punctum for $3 \mathrm{~min}$ to decrease systemic absorption. The differences in pupil diameter between the 2 eyes were calculated by photography
$1 \mathrm{~h}$ after $4 \%$ cocaine or $0.5 \%$ apraclonidine was instilled. Photographs of the pupils were taken with a digital SLR camera (D2H; Nikon Photo Products, Tokyo, Japan) using a 60-mm microlens (Nikon AF $60 \mathrm{~mm} / \mathrm{f2} .8 \mathrm{D}$ ). All photographs were taken at the same photographic distance $(36 \mathrm{~cm})$. With the aid of a high-speed synchronized flash, we fixed the lens aperture (f8) and shutter speed $(1 / 250 \mathrm{~s})$ simultaneously. The photographs were then transferred to a computer. We used Adobe PhotoShop CS (Adobe Systems, Inc., San Jose, CA) software to measure the pupil diameters. Negative values indicate that the pupil with Horner syndrome was smaller than the normal pupil. Positive values indicate that the pupil with Horner syndrome was larger than the normal pupil (reversal of anisocoria).

Any adverse effects related to $0.5 \%$ apraclonidine were recorded. For statistical analysis, we used a Wilcoxon matched-pairs signed-ranks test. $P<0.05$ was considered statistically significant.

\section{RESULTS}

All children with probable Horner syndrome included in this study had unilateral relative miosis that was greater in the dark than in the light with normal papillary responses to direct light. Upper eyelid ptosis 1-2 $\mathrm{mm}$ ipsilateral to the smaller pupil was also present in all cases. Iris heterochroma was noted in 6 patients $(60 \%)$ with Horner syndrome (Table 1).

The mean ( \pm standard deviation) anisocoria values before and after the instillation of $4 \%$ cocaine were: $2.08 \pm 0.48$ and $-2.97 \pm 0.49 \mathrm{~mm}$, respectively $(P=0.0047)$. The mean ( \pm standard deviation) difference in pupil diameters before and after the instillation of $0.5 \%$ apraclonidine were $-2.04 \pm 0.42$ and $+1.08 \pm 0.44 \mathrm{~mm}$, respectively $(P=0.005$; Table 2$)$. The mean anisocoria values before treatment with $4 \%$ cocaine or $0.5 \%$ apraclonidine were not significantly different $(P=0.42)$. All patients showed anisocoria greater than $1 \mathrm{~mm}$ after $4 \%$ cocaine was instilled (Fig. 1A). All patients with Horner syndrome showed positive differences in pupil diameters (reversal of anisocoria) after the instillation of $0.5 \%$ apraclonidine (Fig. 1B). The sensitivity was 1.00 in this study. Conjunctival hyperemia was noted in 2 patients, but systemic adverse effects were not noted during the tests nor were any reported by the patients' parents. 
Table 1. Data on Patients with Horner Syndrome

\begin{tabular}{|c|c|c|c|c|c|c|}
\hline $\begin{array}{l}\text { Patient } \\
\text { no. }\end{array}$ & $\begin{array}{l}\text { Age } \\
\text { (years) }\end{array}$ & Gender & Etiology & $\begin{array}{l}\text { Duration } \\
\text { (years) }\end{array}$ & Cocaine & $\begin{array}{l}\text { Ophthalmological } \\
\text { findings }\end{array}$ \\
\hline 1 & 2.5 & M & Birth trauma & 2.5 & + & PMI \\
\hline 2 & 8 & M & Birth trauma & 8 & + & PMI \\
\hline 3 & 1.5 & M & Birth trauma & 1.5 & + & PMI \\
\hline 4 & 3 & $\mathrm{M}$ & Idiopathic & 3 & + & PMI \\
\hline 5 & 5 & $\mathrm{~F}$ & Idiopathic & 5 & + & PMI \\
\hline 6 & 18 & M & Idiopathic & 10 & + & PM \\
\hline 7 & 10 & M & Idiopathic & 10 & + & PMI \\
\hline 8 & 16 & M & $\begin{array}{l}\text { Hypothalamic } \\
\text { infarction }\end{array}$ & 9 & + & PM \\
\hline 9 & 1.2 & $\mathrm{~F}$ & Neuroblastoma & 0.5 & + & PM \\
\hline 10 & 6 & M & $\begin{array}{l}\text { Radical neck } \\
\text { dissection }\end{array}$ & 2 & + & PM \\
\hline
\end{tabular}

+ , positive result; $\mathrm{P}$, ptosis; $\mathrm{M}$, miosis; $\mathrm{I}$, iris heterochroma.

\section{DISCUSSION}

The pharmacological diagnosis of Horner syndrome using topical cocaine has been the gold standard for years. ${ }^{10,11}$ Because cocaine is a controlled substance, it is difficult to obtain, and because of its short shelf-life, the solution must be made up for each individual patient. We found that parents were often hesitant to allow the use of cocaine as a diagnostic tool when it was suggested during this study. Apraclonidine is unique in having weak but clinically detectable $\alpha 1$ activity, compared with that of other $\alpha 2$-agonists, such as brimonidine tartrate. The effect of $0.5 \%$ apraclonidine in the diagnosis of Horner syndrome is a result of the denervation hypersensitivity of the postsynaptic $\alpha 1$-receptor in the pupil dilator muscle. This effect may be indirectly amplified by the absence of presynaptic $\alpha 2$-receptor activity, which normally downregulates the release of norepinephine into the synaptic junction and thus decelerates $\alpha 1$-stimulated mydriasis. ${ }^{12,13}$ Apraclonidine has shown good sensitivity in the diagnosis of Horner syndrome in previous studies, ${ }^{7,8}$ but no study has compared its effects with those of $4 \%$ cocaine or evaluated its safety in pediatric patients.
Van der Wiel and Van Gijn ${ }^{14}$ compared the anisocoria produced by topical $5 \%$ cocaine in patients with Horner syndrome with that produced in normal subjects and found that an anisocoria value of $1.0 \mathrm{~mm}$ or more was sufficient evidence of Horner syndrome. In an earlier study, ${ }^{11}$ the amount of anisocoria after the instillation of topical cocaine was the best predictor of Horner syndrome. If postcocaine anisocoria exceeded $1 \mathrm{~mm}$, the mean odds ratio for having Horner syndrome was approximately 5990:1 with a $95 \%$ confidence interval of 92:1. In our study, all patients with Horner syndrome showed anisocoria greater than $1 \mathrm{~mm}$ after the instillation of $4 \%$ cocaine.

It has been suggested that, if patients have been previously tested with cocaine to establish a diagnosis of Horner syndrome, further pharmacological testing should be postponed for at least 24-48 $\mathrm{h}$ to allow for the restoration of preexisting anatomical and physiological parameters. ${ }^{15}$ The washout period of apraclonidine is 7-14 days. ${ }^{16}$ In our study, the mean amount of anisocoria before treatment with $4 \%$ cocaine and before treatment with $0.5 \%$ apraclomidine 1 week thereafter did not differ.

Topical aparaclonidine actively dilates the affected pupil but not the normal pupil, making its

Table 2. Mean Difference in Pupil Diameters in Patients With Horner Syndrome Before AND After 4\% Cocaine or 0.5\% Apraclonidine

\begin{tabular}{lcc}
\hline & Before & After \\
\hline $4 \%$ cocaine & $-2.08 \pm 0.47 \mathrm{~mm}$ & $-2.97 \pm 0.48 \mathrm{~mm}$ \\
$0.5 \%$ apraclonidine & $-2.04 \pm 0.42 \mathrm{~mm}$ & $+1.08 \pm 0.44 \mathrm{~mm}$ \\
\hline
\end{tabular}


A

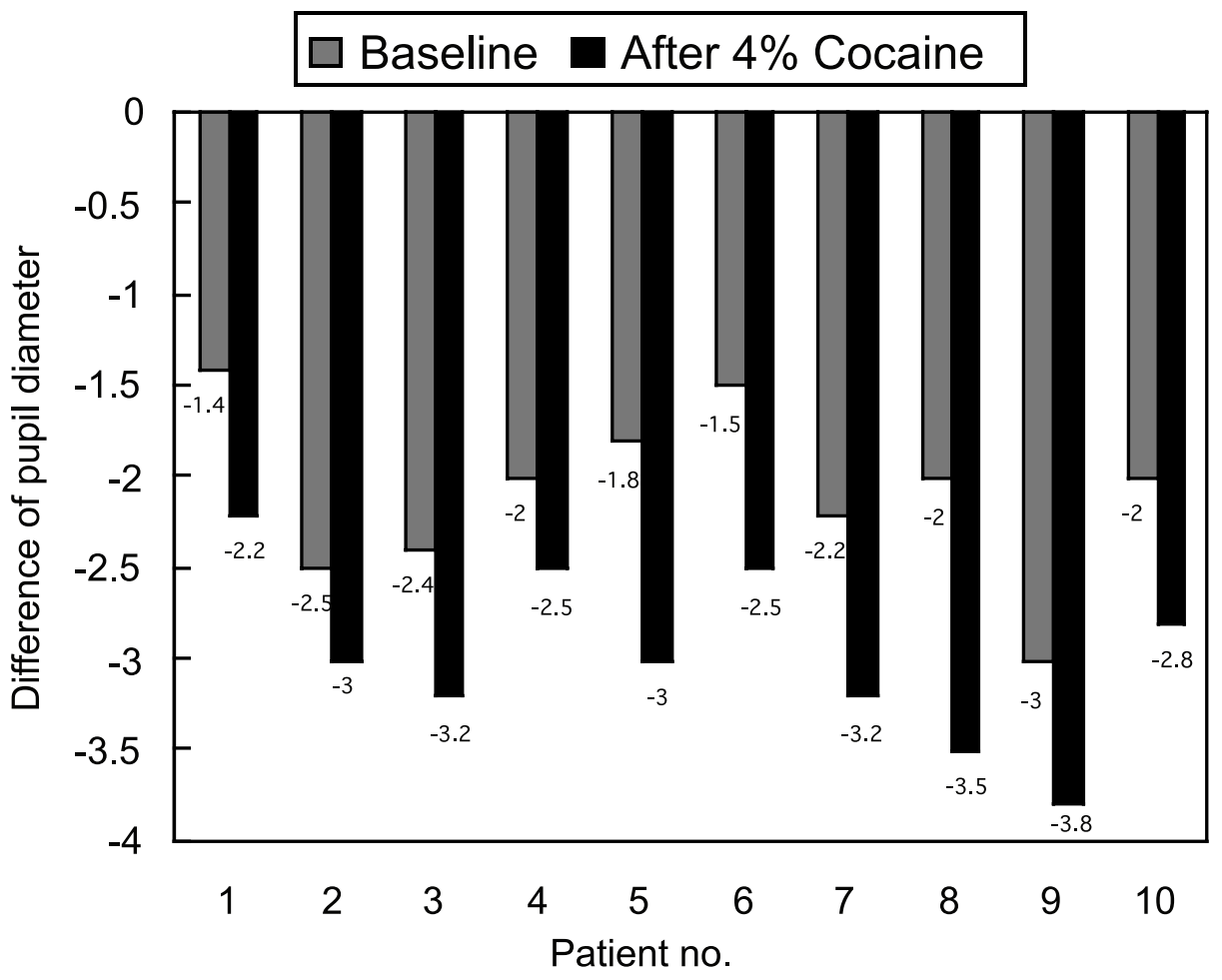

B

\section{Baseline After $0.5 \%$ Apraclonidine}

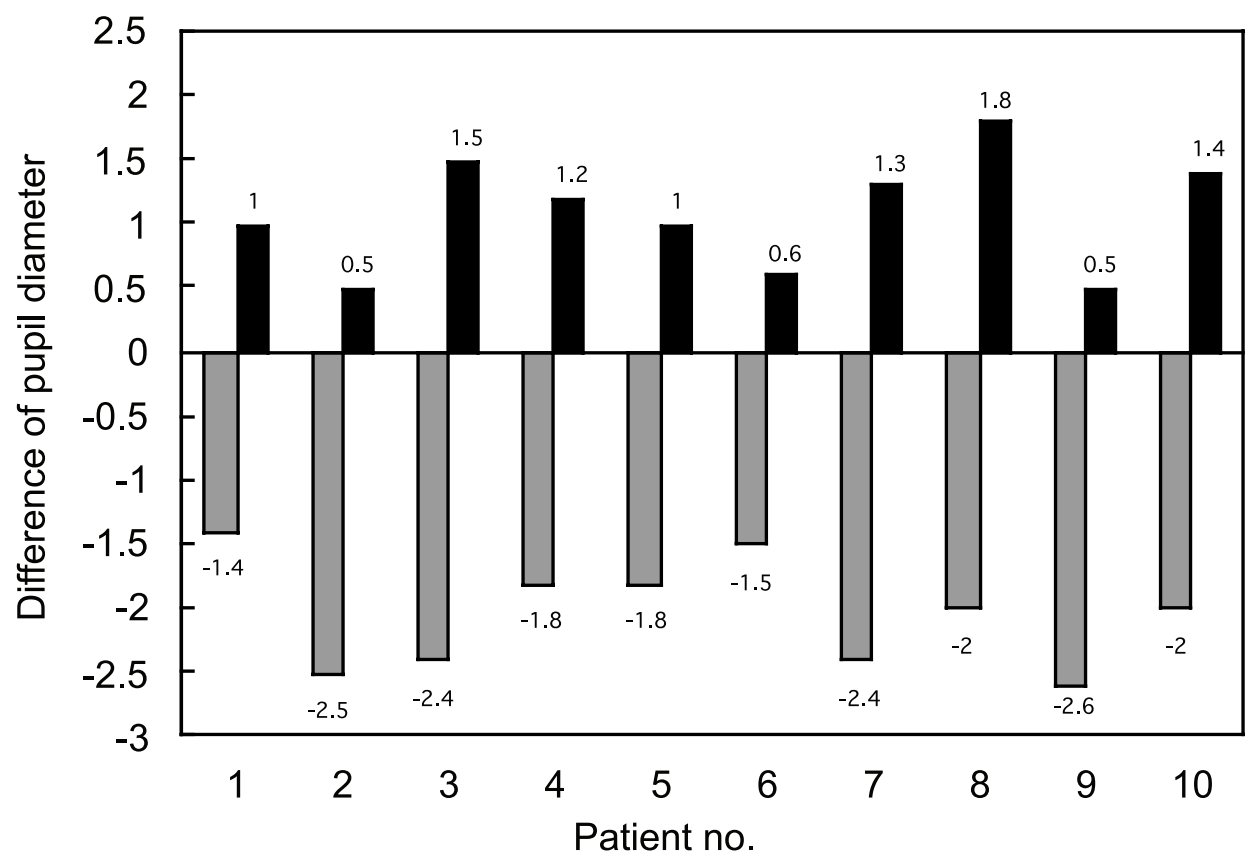

FIG. 1. (A) Anisocoria at baseline and after $4 \%$ cocaine. (B) Anisocoria at baseline and after $0.5 \%$ apraclonidine.

action mydriatic in the affected eye rather than mydriatic in the unaffected eye, as is the case with cocaine testing. Therefore, testing for Horner syndrome using $0.5 \%$ apraclonidine is unlikely to be confounded by mild differences in room illumination before and after its administration. Furthermore, the reversal of anisocoria, even when slight, is easily detected clinically with the naked 
eye. Topical cocaine hydrochloride is increasingly difficult and costly to obtain and is rarely used by ophthalmologists for any purpose other than the diagnosis of Horner syndrome. All our patients with Horner syndrome showed a reversal of anisocoria (range, 0.5-1.8 mm; mean, $1.08 \mathrm{~mm}$ ). Previous studies demonstrated sensitivities of 1.00 and 0.88 when $1 \%$ apraclonidine and $0.5 \%$ apraclonidine, respectively, were used in the diagnosis of Horner syndrome ${ }^{7,8}$ and 1.00 when $0.5 \%$ apraclonidine was tested in the diagnosis of oculosympathetic paresis (OSP). ${ }^{17}$ The design of this study was to investigate the replacement of cocaine with apraclonidine in the diagnosis of Horner syndrome, and the cocaine test was also evaluated at the same time. Our results showed that the sensitivity of $0.5 \%$ apraclonidine, when used in the diagnosis of Horner syndrome, was excellent.

There are many ways to measure pupil size with variable accuracy. Infrared pupilography is considered the most accurate technique ${ }^{16}$ for the measurement of pupil diameter. However, it is often expensive and requires a high level of $\mathrm{co}^{-}$ operation from the patient. Some studies ${ }^{7-9,17}$ have used the pupil gauge on the Rosenbaum pocket to measure pupil diameter to the nearest $0.5 \mathrm{~mm}$; however, the results could be affected by different operators. In our study, many of the subjects were too young to cooperate sufficiently to be treated with infrared pupilography. To achieve a more accurate result, we used a digital SLR camera equipped with a microlens to photograph the pupil. Because we had fixed the photographic distance, we controlled the image magnification rate as well. The pupil size in the image was then measured with image analysis software. We believe that measurements made with digitized and computerized image processing maximally reduces the observational error.

Reports have claimed that $\alpha$-adrenergic receptor agonists used to treat glaucoma in children have caused apnea, bradycardia, hypotension, somnolence, and lethargy. ${ }^{18,19}$ Enyedi and Freedman reported that of 30 children with glaucoma, between 2.4 and 16.8 years of age, who were treated with brimonidine, 2 displayed somnolence and 5 extreme fatigue. ${ }^{19}$ In another report, 1 of 6 children treated with $1 \%$ apraclonidine to dianose Horner syndrome were reported by their parents to be sleepier than usual. ${ }^{9}$ In our study, although conjunctival hyperemia was noted in 2 patients, systemic adverse effects of apraclonidine were not noted during examination nor were reported by the patients' parents. But owing to the small number of patients, a large, prospective study would need to establish the safety of apraclonidine in the diagnosis of children with Horner syndrome.

The aim of our study was merely to investigate the efficacy of $0.5 \%$ apraclonidine in the diagnosis of Horner syndrome. Apraclonidine could not localize the lesion in the sympathetic chain, and further testing with imaging studies (MRI of head/neck, abdominal CT), urine catecholamines, or topical hydroxyamphetamine should be peformed, as Horner syndrome could be the only sign of a potentially life-threatening condition.

\section{CONCLUSIONS}

In summary, our results showed that $0.5 \%$ apraclonidine can be used as a test for Horner syndrome in pediatric patients, with excellent sensitivity and with no systemic adverse effects.

\section{REFERENCES}

1. Thompson, H.S., and Miller, N.R. Disorders of papillary function, accommodation, and lacrimation. In: Walsh, F.B., Hoyt, W.F. eds. Clinical Neuro-Ophthalmology. 5th ed. Baltimore: Williams \& Wilkins, 1969:514-521.

2. Pilley, S.F.J., and Thompson, H.S. Pupillary "dilatation lag" in Horner syndrome. Br. J. Ophthalmol. 59:731-735, 1975.

3. Jeffery, A.R., Ellis, F.J., Repka, M.X., et al. Pediatric Horner syndrome. J. AAPOS 2:159-167, 1998.

4. Thompson, H.S. Diagnosing Horner syndrome. Trans. Sect. Ophthalmol. Am. Acad. Ophthalmol. Otolaryngol. 83:840-842, 1977.

5. Lepore, F.E. Diagnostic pharmacology of the pupil. Clin. Neuropharmacol. 8:27-37, 1985.

6. Van der Wiel, H.L., and Van Gijn, J. The diagnosis of Horner syndrome. Clin. Neurol. Neurosurgr. 90:103-108, 1988.

7. Morales, J., Brown, S.M., Abdul-Rahim, A.S., et al. Ocular effects of apraclonidine in Horner syndrome. Arch. Ophthalmol. 118:951-954, 2000.

8. Brown, S.M., Aouchiche, R., and Freedman, K.A. The utility of $0.5 \%$ apraclonidine in the diagnosis of Horner syndrome. Arch. Ophthalmol. 121:1201-1203, 2003.

9. Bacal, D.A., and Manche, E.E. The role of apraclonidine in the diagnosis of Horner syndrome in pediatric patients. Arch. Ophthalmol. 122:276-279, 2004.

10. Weinstein, J.M., Zweifel, T.J., and Thompson, H.S. Congenital Horner syndrome. Arch. Ophthalmol. 98: 1074-1078, 1980. 
11. Kardon, R.H., Denison, C.E., Brown, C.K., et al. Critical evaluation of the cocaine test in the diagnosis of Horner syndrome. Arch. Ophthalmol. 108:384-387, 1990.

12. Miller, P.E., and Rhaesa, S.L. Effect of topical administration of $0.5 \%$ apraclonidine on intraocular pressure, pupil size, and heart rate in clinically normal cats. Am. J. Vet. Res. 57:83-86, 1996.

13. Crosson, C.E., Heath, A.R., DeVies, G.W., et al. Pharmacological evidence for heterogeneity of ocular alpha-2 adrenoceptors. Curr. Eye Res. 11:963-970, 1992.

14. Van der Wiel, H.L., and Van Gijn, J. The diagnosis of Horner syndrome: Use and limitation of the cocaine test. J. Neuro. Sci. 73:311-316, 1986.

15. Gillum, W.N. Sympathetic stimulators and blockers. Ophthalmic Semin. 2:283-326, 1977.

16. Wilhelm, H., and Wilhelm, B. Clinical applications of pupillography. J. Neuro-Ophthalmol. 23:42-49, 2003.

17. Koc, F., Kavuncu, S., Kansu, T., et al. The sensitivity and specificity of $0.5 \%$ apraclonidine in the diagnosis of oculosympathetic paresis. Br. J. Ophthalmol. 89:1442-1444, 2005.
18. Carlsen, J., Zabriskie, N., Known, Y., et al. Apparent central nervous system depression in infants after the use of topical brimonidine. Am. J. Ophthalmol. 128:255-256, 1999.

19. Enyedi, I.B., and Freedman, S.F. Safety and efficacy of brimonidine in children with glaucoma. J. AAPOS. 5:281-284, 2001.

Received: January 19, 2006

Accepted: March 2, 2006

Reprint Requests: Chih-Hsien Hsiao Department of Ophthalmology Tri-Service General Hospital National Defense Medical Center 325, Section 2, Cheng-Kung Road Taipei 114, Taiwan Republic of China

E-mail: ddff36@yahoo.com.tw 